\title{
ARBORIZAÇÃO URBANA EM REGISTRO/SP: LEITURA E PERCEPÇÕES AMBIENTAIS
}

URBAN TREES IN REGISTRO/SP: ENVIRONMETAL READING AND PERCEPTIONS

ARBORIZACIÓN URBANA EN REGISTRO/SP: LECTURA Y PERCEPCIONES AMBIENTALES

Douglas Gallo

Professor Mestre, IFSP, Brasil

Doutorando em Urbanismo, PROURB/FAU/UFRJ, Brasil

douglas.luciano@yahoo.com.br

Léa Yamaguchi Dobbert Professora Doutora, IFSP, Brasil lea.dobbert@gmail.com 


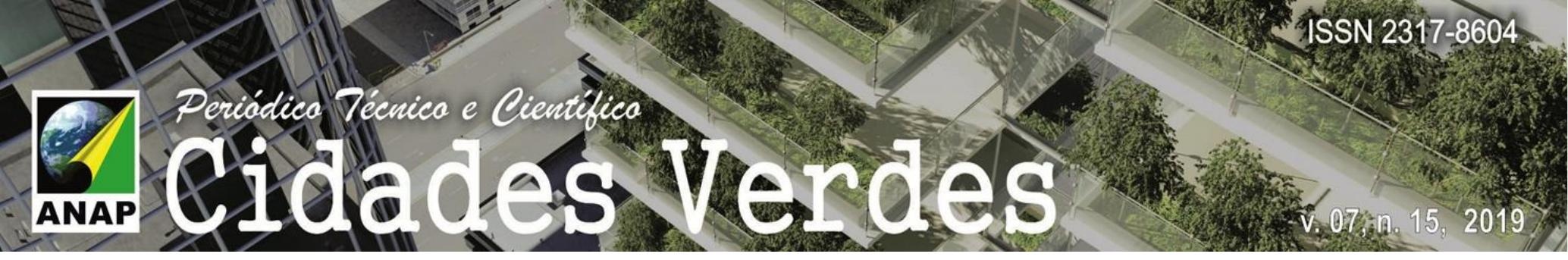

\section{RESUMO}

Este artigo tem por objetivo realizar uma leitura do estado atual da arborização urbana de Registro/SP e conhecer o nível de satisfação dos moradores com a arborização existente. Para tanto foi realizada uma amostragem sistemática das quadras com intensidade amostral de 10\%, totalizando 42 quarteirões analisados. A variável principal foi a abundância de árvores, expressa pelo número de árvores por quilômetro de calçadas. Como variáveis qualitativas foram avaliados o porte arbóreo e a compatibilidade das espécies utilizadas com o logradouro. Para analisar a percepção/satisfação dos moradores com arborização foram entrevistados 164 cidadãos, questionados sobre sua satisfação com a arborização da rua onde residiam e da cidade em geral. Os principais resultados indicaram a presença de 8 árvores por quilômetro de calçada e a prevalência da espécie Ficus benjamina, com 33,82\% do total de árvores inventariadas. Quanto às características da arborização existente, 36,03\% das árvores eram de grande porte e $42,65 \%$ dos indivíduos eram inadequados ao local. Em relação à satisfação com a arborização da rua de residência $41,46 \%$ estavam muito insatisfeitos, mas em relação à arborização total da cidade 33,54\% eram indiferentes. Conclui-se que falta planejamento e gestão para a arborização urbana em Registro/SP, apresentando-se como deficitária e percebida como tal pelos moradores.

PALAVRAS-CHAVE: Arborização urbana. Espaços livres. Percepção ambiental.

\section{ABSTRACT}

This study aimed to make a reading of the current state of urban trees in Registro/SP, and to know the level of satisfaction of the residents with the urban trees. We did a systematic sampling or the blocks with sampling intensity of $10 \%$, totaling 42 blocks analyzed. The main variable was the abundance of trees, expressed by the number of trees per kilometer of sidewalks. As qualitative variables were evaluated the tree size and the compatibility of the species used with the public space. To analyze the perception/satisfaction of the residents with urban trees, we interviewed 164 citizens, we questioned about their satisfaction with the urban trees of the street where they lived and of the city in general. The results indicate the presence of 8 trees per kilometer or sidewalk, prevalence of Ficus benjamina with $33.82 \%$ of the total trees. Regarding the tree size, $36.03 \%$ of the trees were large and $42.65 \%$ of the individuals were inadequate and $33.09 \%$ were partially compatible with the site. Regarding the satisfaction with urban trees of the street or residence, $41.46 \%$ were very dissatisfied, but in relation to the total urban trees of the city, $33.54 \%$ were indifferent. It is concluded that planning and management for urban trees in Registro/SP is lacking, presenting itself as a deficit and perceived as such by the residents.

KEYWORDS: Urban trees. Free spaces. Environmental perception.

\section{RESUMEN}

El propósito de este ensayo es realizar una lectura del estado actual de la arborización urbana de Registro/SP y conocer el nivel de satisfacción de los habitantes con la arborización existente. Para ello se realizó un muestreo sistemático de las cuadras con intensidad muestral del $10 \%$, totalizando 42 cuadras analizadas. La variable principal fue la abundancia de árboles, expresada por el número de árboles por kilómetro de calzadas. Como variables cualitativas fueron evaluados el porte arbóreo y la compatibilidad de las especies utilizadas con el terreno. Para analizar la percepción / satisfacción de los habitantes con arborización fueron entrevistados 164 ciudadanos, cuestionados sobre su satisfacción con la arborización de la calle donde residían y de la ciudad en general. Los principales resultados indican la presencia de 8 árboles por kilómetro de calzada, prevalencia de la especie Ficus benjamina con el 33,82\% del total de árboles inventariados. En cuanto al porte arbóreo el 36,03\% de los árboles eran de gran porte y el $42,65 \%$ de los individuos eran inadecuados y el 33,09\% parcialmente compatible con el local. En cuanto a la satisfacción con la arborización de la calle de residencia $41,46 \%$ estaban muy insatisfechos, pero en relación a la arborización total de la ciudad el 33,54\% eran indiferentes. Se concluye que falta planificación y gestión para la arborización urbana en Registro, presentándose como deficitaria y percibida como tal por los moradores.

PALABRAS CLAVE: Arborización urbana. Espacios libres. Percepción ambientale. 


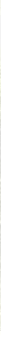

\section{METODOLOGIA}

O estudo foi realizado na cidade de Registro (Figura 1), localizada no Vale do Ribeira, estado de São Paulo, Brasil, entre as coordenadas geográficas $24^{\circ} 29^{\prime} 15^{\prime \prime}$ de latitude sul, $47^{\circ} 50^{\prime} 37^{\prime \prime}$ de longitude oeste, com altitude média de $25 \mathrm{~m}$. A cidade possui um clima quente e temperado, com média anual de temperatura na ordem de $22^{\circ} \mathrm{C}$ e média de pluviosidade de $1.626 \mathrm{~mm}$. O município tem uma extensão territorial de aproximadamente $722 \mathrm{~km}^{2}$, dos quais $78 \mathrm{~km}^{2}$ são de área urbana, segundo o censo de 2010 a população era 54.261 habitantes, sendo estimada em 56.249 habitantes em 2018. Apresenta 87,2\% de domicílios com esgotamento sanitário adequado e 33,5\% dos domicílios urbanos em vias públicas urbanizadas (presença de bueiro, calçada, pavimentação e meio-fio). As vias públicas com arborização, segundo o IBGE, representam 47,6\% do total, quando comparada com as demais cidades do estado está na posição 606 de 646, no quesito arborização, e sua posição nacional é de 4.215 de um total de 5.570 municípios. Para o instituto, uma via é considerada arborizada se em alguma das calçadas/passeios de suas faces ou no canteiro central existir árvores, mesmo que apenas em parte desta (IBGE, 2010).

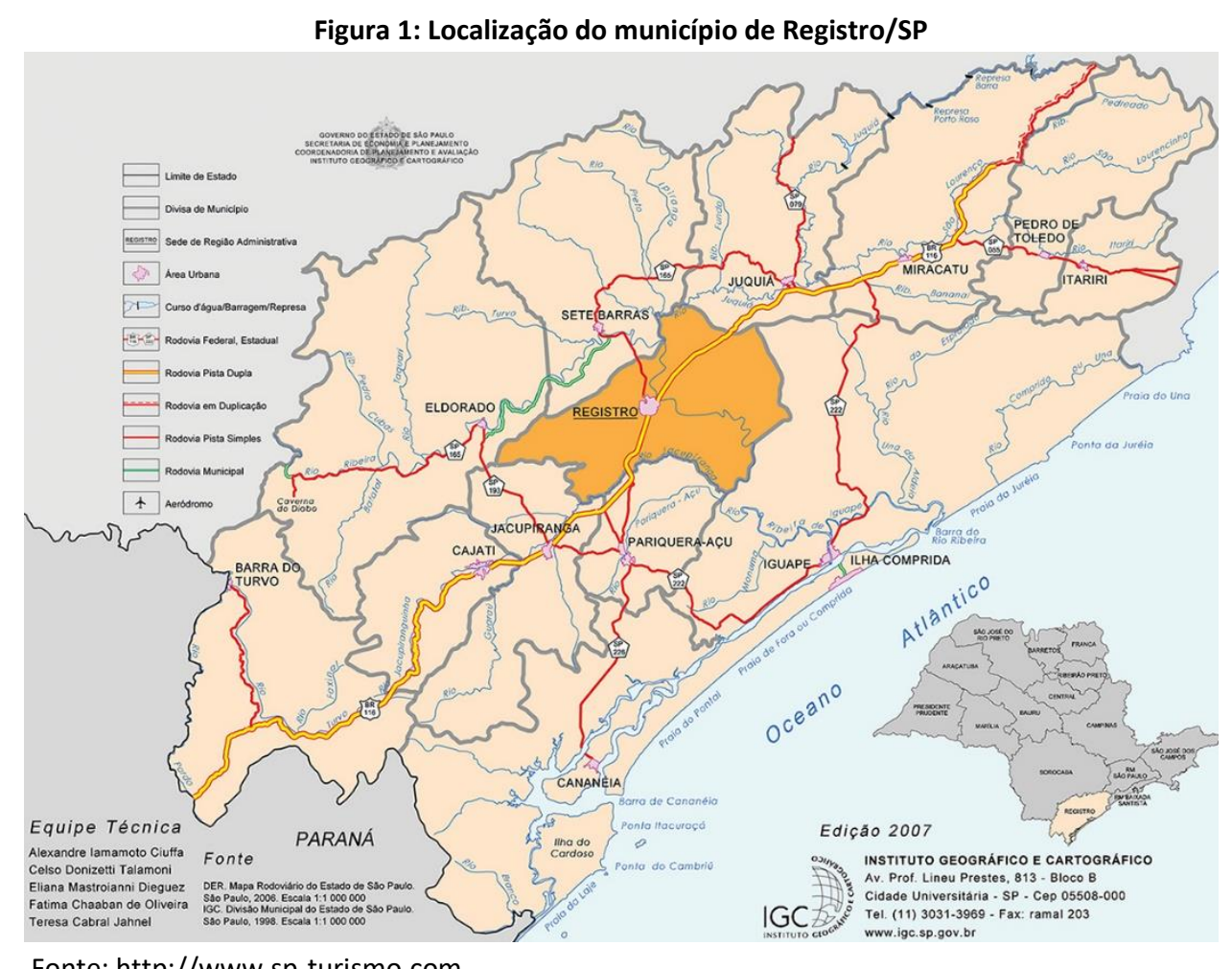

Fonte: http://www.sp-turismo.com

A arborização urbana é essencialmente dependente do planejamento e desenho urbanos, especialmente das características espaciais do sistema viário, condicionando suas características quanti-qualitativas (MILANO, 1994). Os levantamentos se dividem entre os inventários totais, ou censo, e inventários por amostragem, sendo que o primeiro caso em geral é inviável, dispendendo muitos recursos e tempo, adotando-se, normalmente, o segundo método. 


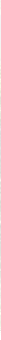

Entre os sistemas de amostragem o mais comum é o aleatório (MILANO, 1994), porém, Meneghetti (2003) considera a amostragem sistemática mais exata, garantindo uma distribuição mais uniforme das unidades amostrais na área de estudo. $O$ presente estudo utilizou a amostragem sistemática, tendo o quarteirão como unidade amostral, denominada "quadra", buscando-se uma intensidade amostral de 10\% (GALLO e LOGSDON, 2018). Inicialmente, foram numeradas sequencialmente todas as quadras da cidade de Registro/SP, com auxílio de softwares (Google Maps e AutoCad 2014), totalizando 418 unidades. Em seguida, foi realizado o sorteio do primeiro quarteirão da amostra, o número 3 (três), sendo os demais determinados sistematicamente $(3,13,23,33 \ldots, 413)$ conformando um universo amostral de 42 (quarenta duas) quadras (Figura 2). Eram excluídas as quadras compostas por área verde (praças, parques etc.), sendo considerada a quadra subsequente, para a coleta de dados.

Figura 2: Cartografia da cidade de Registro/SP, indicando as quadras amostradas

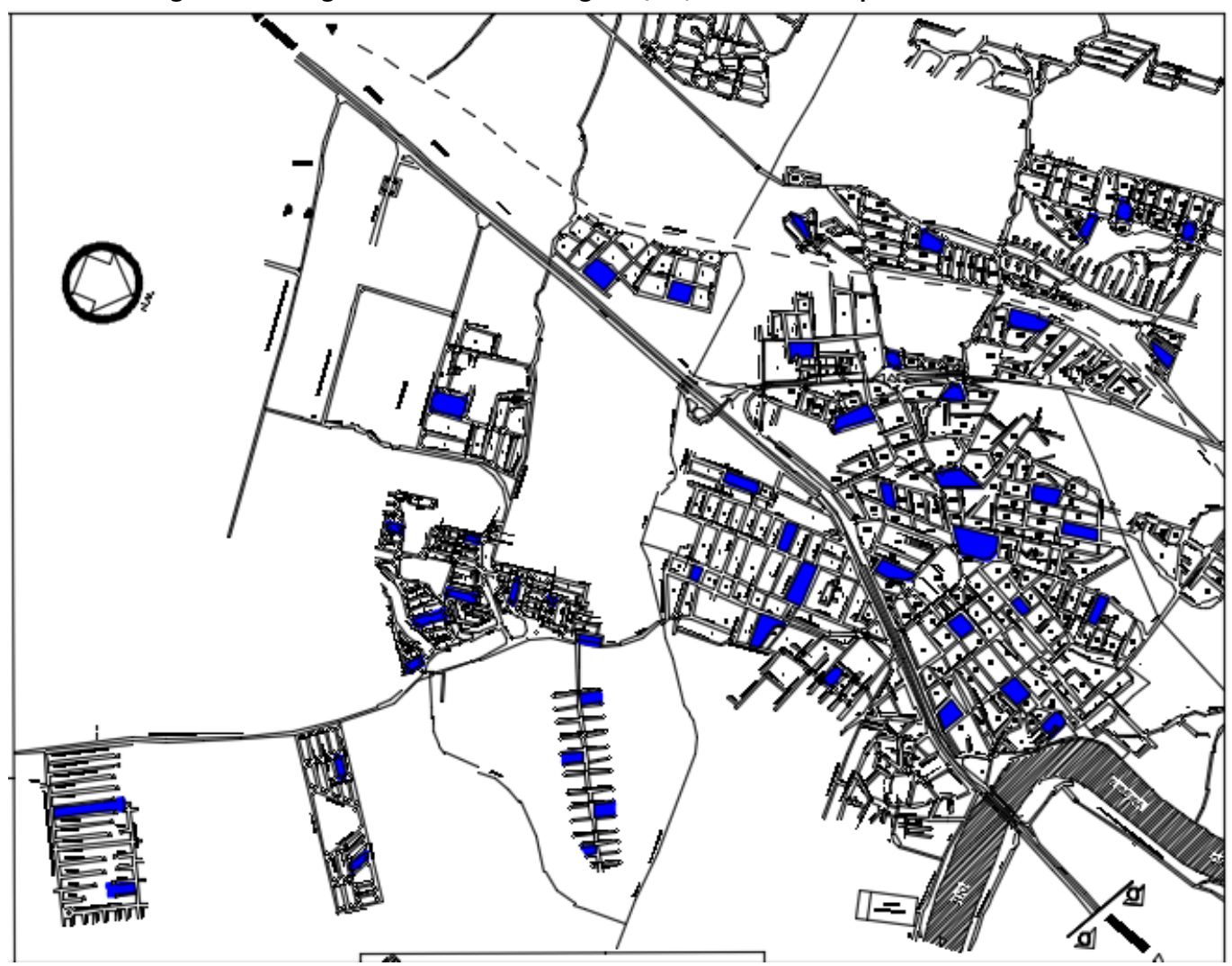

Fonte: Elaborado pelos autores

A variável principal do estudo foi a abundância de árvores, expressa pelo número de árvores por quilômetro de calçadas (MENEGHETTI, 2003), por ser considerada uma variável muito viável para inventários de arborização urbana, com manejo simples e rápido. Seu cálculo é feito pela razão entre o número total de árvores amostradas na área de estudo e o somatório dos comprimentos das calçadas dos quarteirões que compõe a amostra, cálculo feito com auxílios dos softwares.

As variáveis qualitativas (compatibilidade e porte arbóreo) foram adaptadas dos estudos de Meneghetti (2003), Mascaró e Mascaró (2005) e Romero (2001). Os dados foram coletados durante a pesquisa de campo, com auxílio de uma ficha de coleta. Foram realizadas: medições, levantamento fotográfico, avaliação dos aspectos espaciais e compatibilidade das árvores com o logradouro público, bem como a identificação das 


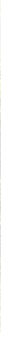

espécies. As variáveis utilizadas neste estudo foram: variáveis relacionadas à quadra (identificação do local de estudo); variáveis relacionadas ao espécime (identificação da árvore analisada; porte da árvore (pequeno porte - alturas até a rede telefônica / médio porte - alturas entre a rede telefônica e a rede elétrica secundária / grande porte - alturas que ultrapassam a rede secundária); compatibilidade da espécie escolhida com o logradouro (A - adequada; B - pequena para o espaço disponível; C - parcialmente compatível, devido a presença de fiação/árvores de crescimento monopodial e árvores submetidas a podas drásticas; D - parcialmente compatível, devido a outros motivos, como frutos grandes, palmeiras, arbustos etc.; $\mathrm{E}$ - inadequada devido ao sistema radicular; $\mathrm{F}$ - grande para o espaço disponível).

Foi realizada também uma pesquisa de satisfação com a arborização urbana, sendo entrevistados moradores da cidade de Registro, escolhidos aleatoriamente, entre indivíduos que estavam utilizando os principais espaços públicos da cidade e nos bairros onde foi realizada a avaliação da arborização de acompanhamento viário. Os entrevistados aceitaram participar da pesquisa voluntariamente, após os objetivos serem explicados e assinarem o termo de consentimento livre e esclarecido.

O questionário abordava também outras questões, referentes à percepção e apropriação do espaço público urbano, porém para o recorte temático deste artigo foram consideradas duas dimensões: a satisfação com a arborização urbana da rua da residência onde habitavam e a satisfação com o estado geral de arborização municipal, utilizando-se uma escala de 1 (um) a 5 (cinco), sendo 1 - muito insatisfeito, e 5 - muito satisfeito.

\section{RESULTADOS}

Foram analisadas quarenta e duas quadras da cidade de Registro/SP, representando dez por cento do total de quarteirões aventados com auxílio de cartografia oficial do município. As quadras amostradas foram visitadas, sendo que nenhuma precisou ser descartada do estudo, de acordo com os critérios de exclusão. As visitas a campo foram realizadas no período de março a julho de 2017 , sendo percorridas todas as faces dos quarteirões e realizadas análises e avaliações da arborização e das condições nas quais se apresentava.

O comprimento linear total das quarenta e uma quadras foi aferido com auxílio do programa AutoCad 2014, totalizando 16.485,60 metros de calçadas. Neste percurso foram contabilizados 136 (centro e trinta e seis) indivíduos arbóreos, representando um média de uma árvore a cada $121 \mathrm{~m}$ (cento e vinte e um metros), ou aproximadamente oito árvores por quilômetro de acompanhamento viário ( 8 árvores $/ \mathrm{km}$ de calçada).

As árvores foram identificadas in loco, quando sua identificação não foi possível no momento do campo, o espécime foi fotografado e coletada amostras para posterior identificação, com auxílio de bibliografia especializada. A espécie mais prevalente na área estudada foi a fícus (Ficus benjamina), num total de 46 (quarenta e seis) indivíduos, representando $33,82 \%$ do total inventariado. A segunda espécie mais prevalente foi o ipê (Tabebuia sp) com 13 (treze) indivíduos, num total de 9,56\% da arborização de acompanhamento viário da cidade. Vinte e oito indivíduos não foram identificados, representando $20,59 \%$ do total, a distribuição completa das árvores encontradas se encontra na Tabela 1. 
Tabela 1: Distribuição das espécies inventariadas na cidade de Registro/SP

\begin{tabular}{llccc}
\hline \multicolumn{1}{c}{ Nome popular } & \multicolumn{1}{c}{ Nome científico } & $\begin{array}{c}\text { Número de } \\
\text { indivíduos }\end{array}$ & $\begin{array}{c}\text { Frequência } \\
\text { (\%) }\end{array}$ & $\begin{array}{c}\text { Frequência } \\
\text { acumulada }\end{array}$ \\
\hline Fícus & Fícus benjamina & 46 & 33,82 & 33,82 \\
Ipê & Tabebuia sp & 13 & 9,56 & 43,38 \\
Palmáceas & Aracacea sp & 11 & 8,09 & 51,47 \\
Coco da Bahia & Cocos nucifera & 11 & 8,09 & 59,56 \\
Sibipiruna & Caesalpinia pluviosa & 09 & 6,62 & 66,18 \\
Areca bambu & Dypsis lutescens & 06 & 4,41 & $\mathbf{7 0 , 5 9}$ \\
Pata de vaca & Bauhinia forficata & 06 & 4,41 & $\mathbf{7 5 , 0 0}$ \\
Pitangueira & Eugenia uniflora & 06 & 4,41 & $\mathbf{7 9 , 4 1}$ \\
Não identificada & -------- & 28 & $\mathbf{2 0 , 5 9}$ & 100,00 \\
\hline Total & -------- & $\mathbf{1 3 6}$ & & $\mathbf{1 0 0 , 0 0}$ \\
\hline Fonte: & & & &
\end{tabular}

Fonte: elaborado pelos autores

Em relação ao porte arbóreo, analisado em comparação com a rede elétrica existente no local, a distribuição entre indivíduos de porte baixo, médio ou grande não foi muito dispare, porém, o maior número de indivíduos, 49 (quarenta e nove) representando 36,03\% do total, apresentava um porte alto, ultrapassando a fiação elétrica secundária, a Tabela 2 apresenta a distribuição geral.

A compatibilidade das espécies utilizadas para a arborização das calçadas foi analisada, apresentando apenas 14 (quatorze) árvores consideradas adequadas, segundo a observação dos critérios de análise, o que representa $10,29 \%$ do total. Pode-se considerar que a maioria das espécies, 42,65\%, são inadequadas para o local de plantio, com 58 (cinquenta e oito) árvores entre grandes para o espaço ou inadequadas, segundo critérios observados. As distribuições das compatibilidades dos espécimes estudados com o local de plantio encontram-se apresentados na Tabela 3.

Tabela 2: Distribuição dos indivíduos arbóreos de acordo com o porte, Registro/SP

\begin{tabular}{lccc}
\hline \multicolumn{1}{c}{ Porte arbóreo } & $\begin{array}{c}\text { Altura } \\
\text { (metros) }\end{array}$ & $\begin{array}{c}\text { Frequência } \\
\text { absoluta }\end{array}$ & $\begin{array}{c}\text { Frequência } \\
\text { relativa }\end{array}$ \\
\hline A - pequeno porte & 0,0 a 4,5 & 42 & 30,88 \\
B - médio porte & 4,5 a 6,7 & 45 & 33,09 \\
C- grande porte & $>6,7$ & 49 & 36,03 \\
\hline Total & --- & $\mathbf{1 3 6}$ & $\mathbf{1 0 0 , 0 0}$ \\
\hline
\end{tabular}

Fonte: Elaborado pelos autores

Tabela 3: Compatibilidade das espécies utilizadas na arborização de acompanhamento viário e o local de plantio, Registro/SP

\begin{tabular}{lcc}
\hline Compatibilidade & $\begin{array}{c}\text { Frequência } \\
\text { absoluta }\end{array}$ & $\begin{array}{c}\text { Frequência } \\
\text { relativa }\end{array}$ \\
\hline A - Adequada para o espaço & 14 & 10,29 \\
B - Pequena para o espaço & 19 & 13,97 \\
C- Parcialmente compatível, devido à presença de fiação & 37 & 27,21 \\
D - Parcialmente compatível, devido a outros motivos & 08 & 5,88 \\
E- Inadequado devido ao sistema radicular & 39 & 28,68 \\
F-Grande para o espaço disponível & 19 & 13,97 \\
\hline Total & 136 & $\mathbf{1 0 0 , 0 0}$ \\
\hline
\end{tabular}

Fonte: Elaborado pelos autores 


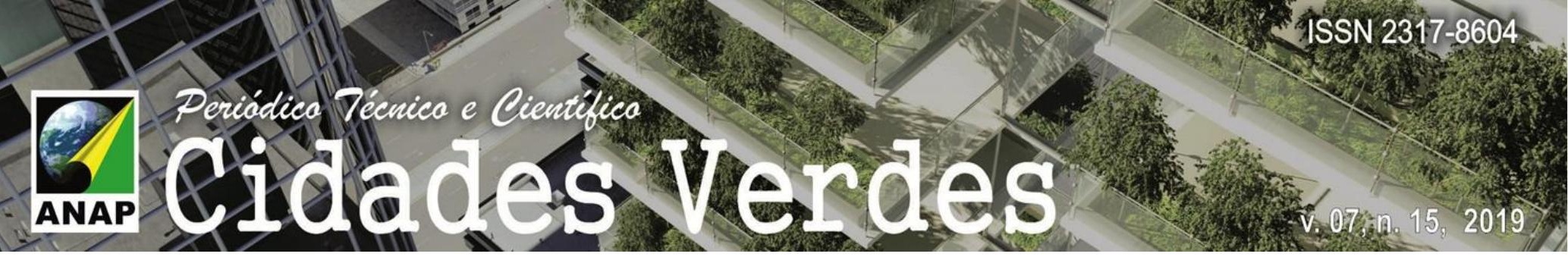

Os resultados apresentados na Tabela 4 são da pesquisa de satisfação em relação a arborização urbana. Foram entrevistados 164 (cento e sessenta e quatro) moradores da cidade, observou-se que a maioria da população se encontra insatisfeita com a arborização de acompanhamento viário de Registro/SP. Mais da metade da população $(55,48 \%)$ mostrou-se insatisfeita ou muito insatisfeita com a arborização da rua onde mora, e $45,12 \%$ dos entrevistados referiu não estarem satisfeitos com a arborização da cidade, de forma geral. Apenas nove entrevistados $(5,49 \%)$ referiram estarem muito satisfeito com a arborização apresentada pela cidade de Registro/SP.

Tabela 4: Nível de satisfação em relação à arborização da rua de residência e da arborização geral da cidade, residentes em

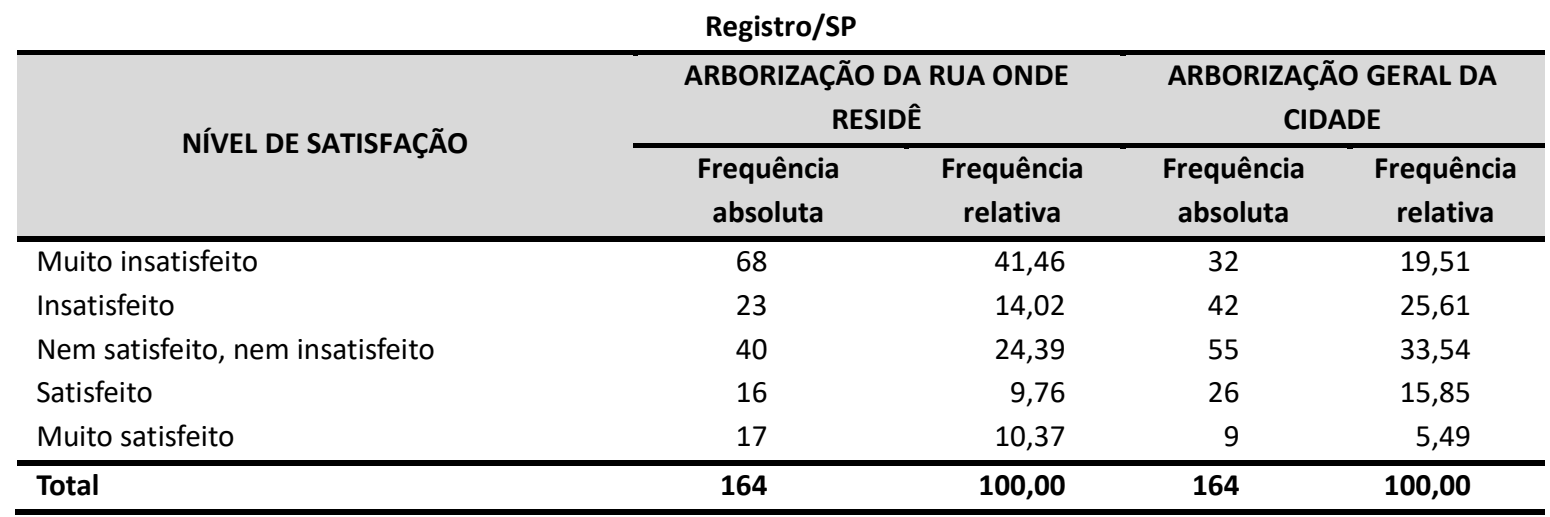

Fonte: Elaborado pelos autores

\section{DISCUSSÃO}

Ao analisar a variável abundância de árvores na cidade de Registro/SP, observamos uma grande deficiência na quantidade de indivíduos arbóreos, a média de 8 árvores por quilômetro de calçada está muito aquém do recomendado pela Sociedade Brasileira de Arborização Urbana (SBAU), que é de 100 indivíduos por quilômetro de calçada (PAIVA, 2009). Se considerarmos também, a razão entre a quantidade de árvores inventariada - 136 indivíduos - pelo número de quarteirões - total de 42 - encontramos uma média de 3,24 árvores por quarteirão. A figura 3 apresenta uma representação esquemática da atual situação da arborização urbana em registro (a) em comparação com o ideal preconizado (b), é possível observar a diferença em relação ao sombreamento esperado por uma boa arborização. 


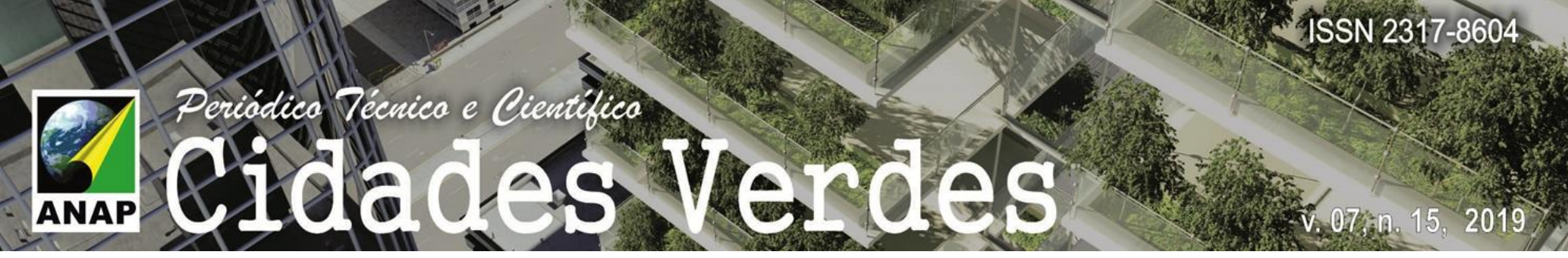

Figura 3: Maquete esquemática, representando a arborização de acompanhamento viário em Registro a) a situação atual e b) situação desejável

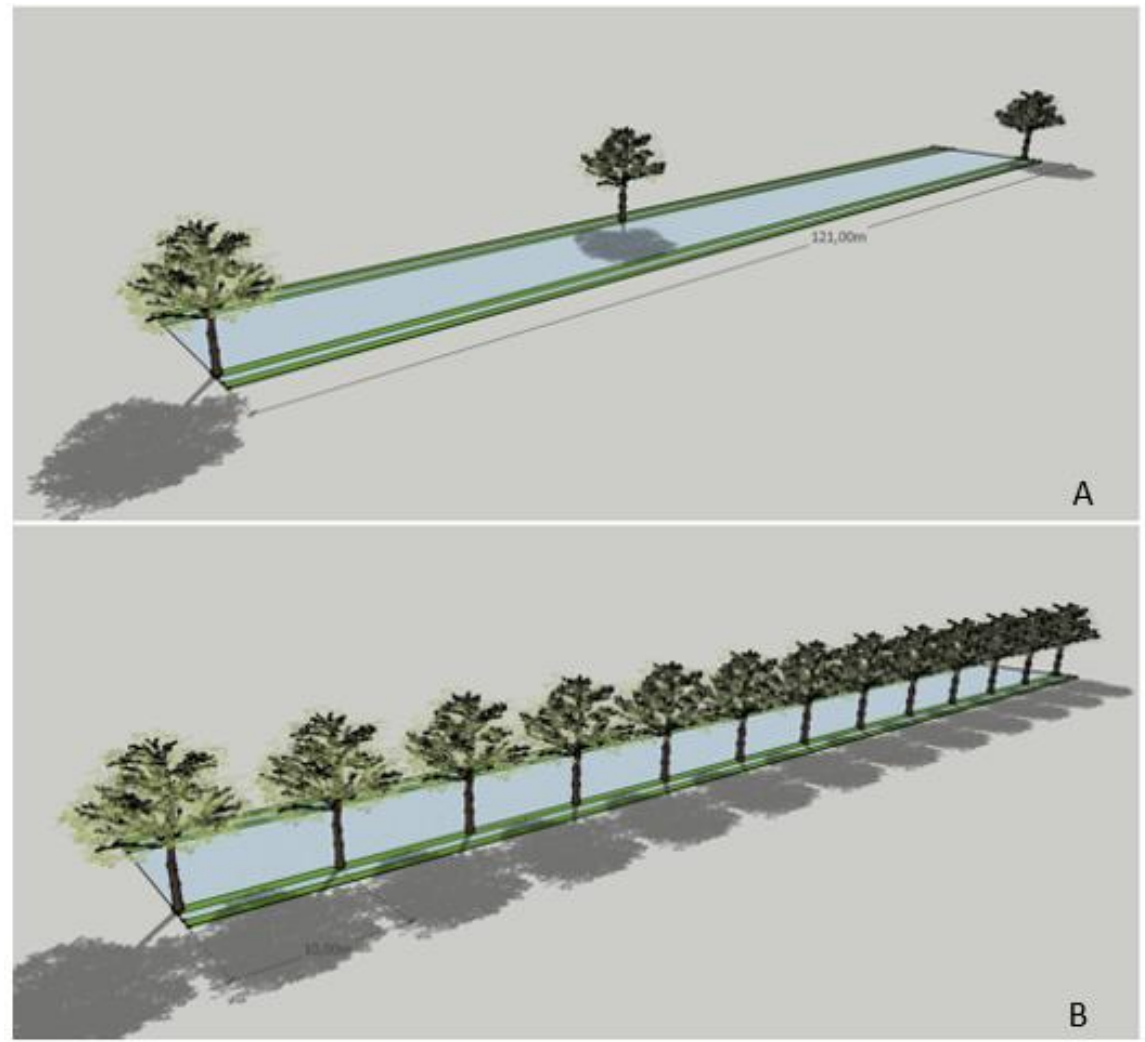

Fonte: Elaborado pelos autores

Considerando que uma quadra padrão costuma ter quatro faces, nem todas as faces das quadras apresentam se quer um indivíduo arbóreo, em média. Outra inferência que evidencia este dado, é que uma quadra média costuma ter $100 \mathrm{~m}$ de extensão linear, e os dados de Registro sugerem 1 árvores a cada 121,10 m. Outros estudos, utilizando a mesma metodologia, mesmo não apresentando o valor ideal, ainda apresentaram valores mais expressivos: Campo Grande com 39,73 árvores/km (GALLO e GUARALDO, 2017), Três Lagoas/MS (61,51 árvores/km), Ponta Porã/MS (70,57 árvores/km), Aquidauana/MS (77,64 árvores/km) e Dourados/MS (79,84 árvores/km) (GALLO e GUARALDO, 2015), em Santo/SP foi encontrada 38,94 árvores/km (MENEGHETTI, 2003).

Em relação à prevalência de algumas espécies, observou-se uma forte concentração de uma espécie em particular, a Ficus benjamina (ficus) representando $33,82 \%$ do total de árvores plantadas nas calçadas. A falta de diversidade arbórea pode acarretar muitos problemas para o planejamento e gestão da arborização, especialmente em relação à susceptibilidade a pragas e doenças, com forte propagação em caso de contaminações. Muitos autores admitem que uma única espécie não deveria ultrapassar mais de $15 \%$ da população total, garantindo assim maior variabilidade (MELO, LIRA FILHO e RODOLFO JÚNIOR, 2007; RODOLFO JÚNIOR et al, 2008).

A grande concentração de poucas espécies é fato recorrente na arborização urbana brasileira, Gallo e Guaraldo (2010) encontraram em Campo Grande/MS alta prevalências de duas espécies, oiti (Moquilea tomentosa) com 27,44\% e fícus (Ficus benjamina) com 20,75\% do total. No estado de Mato Grosso do Sul o oiti (Moquilea tomentosa) representava $63,15 \%$ da arborização urbana de Aquidauana, $78,64 \%$ em Três 
Lagoas, e a sibipiruna (Caesalpinia peltophoroides) 38,45\% em Dourados e 19,97\% em Ponta Porã (GALLO e GUARALDO, 2015). Em Silveira Martins/RS, o ipê roxo (Handroanthus heptaphyllus) representava 19,26\% das espécies (BACKERS et al, 2011), em Cataguases/MG a espécie oiti (Moquilea tomentosa) apresentava frequência de 43,42\% (PAULA et al, 2015), em Baixio/CE o nim indiano (Azadirachta indica) representava 68\% do total de indivíduos (CRISPIM et al, 2017).

Quanto ao porte das árvores, foi observado um equilíbrio entre as três classificações consideradas (Tabela 2), diferindo de outras regiões, como Campo Grande/MS, com $69,61 \%$ dos indivíduos de pequeno porte (GALLO e GUARALDO, 2010) e no estado de Mato Grosso do Sul, 68,71\% das árvores com pequeno porte em Três Lagoas e 57,81\% em Ponta Porã, em Dourados a maioria das árvores $(48,24 \%)$ apresentavam porte alto, e em Aquidauana predomínio de pequeno porte seguida de perto pelas de porte mediano, 44,63\% e 43,56\%, respectivamente (GALLO e GUARALDO, 2015).

O presente estudo encontrou que a maioria das árvores inventariadas são incompatíveis com o local onde foram plantadas, seja devido ao sistema radicular $(28,68 \%)$, seja pela presença de fiação $(27,21 \%)$ ou mesmo por serem grandes para o espaço disponível (13,97\%). Todas estas questões de incompatibilidade estão relacionadas com o planejamento da arborização, indicando tanto escolhas de espécimes equivocados, quanto dimensionamento das vias e, principalmente, das calçadas inadequados. Evidencia-se assim a importância de instrumentos de planejamento como um Plano Diretor de Arborização (PDAU) em consonância com o Plano Diretor Municipal (SEMA, 2014; CAMPO GRANDE, 2010; RIO DE JANEIRO, 2015).

Em relação a percepção dos moradores quanto à arborização urbana de Registro/SP, observa-se uma baixa satisfação com seu estado atual, o que seria esperado, ao confrontá-la com a variável abundância de árvores, apresentando uma quantidade de árvores muito abaixo do recomendado. No estudo de Pizziolo et al (2014), nenhum dos entrevistados percebeu um dos bairros analisados como bem arborizado, enquanto na região central $97 \%$ dos entrevistados percebiam-no como muito arborizado, o que também refletia os altos índices de arborização da região central e uma grande diferença intraurbana, marca das desigualdades socioespaciais das cidades brasileiras.

Em estudo conduzido em Macapá, por Castro e Dias (2013), 98\% da população entrevistada no Loteamento Amazonas e $68 \%$ do Bairro Cidade Nova consideraram suas ruas pouco arborizadas, o estudo aventou como principal fator a falta de espaço nas calçadas para o plantio. Em relação à arborização geral da cidade, $54 \%$ dos macapaenses consideraram a cidade pouco arborizada. Em Aracaju, as percepções boas e regulares foram mais prevalentes, sendo 35,10\% e 34,55\%, respectivamente (FRANÇA; SANTOS e GOMES, 2012). Em Santa Maria, no bairro Camobi, foram encontradas percepções de uma arborização razoável por 49,2\% dos entrevistados, seguido por 38,5\% considerando-a pouco arborizada (ROPPA et al, 2007). Os estudos apontam para a importância de considerar a percepção ambiental dos moradores para a compreensão das interrelações entre o homem e o ambiente (SANTOS et al, 2018).

\section{CONCLUSÃO}

Os benefícios que uma arborização urbana, bem planejada e gerida de forma eficiente, trazem para a ambiência e qualidade de vida urbanas são inegáveis, especialmente para uma cidade de clima quente como Registro/SP. Os dados encontrados apontam para um planejamento deficiente da arborização de acompanhamento viário, com média de árvores por quilômetro de calçadas muito abaixo do preconizado pela Sociedade Brasileira de Arborização Urbana. Para que a cidade alcançasse uma arborização adequada seria necessário, em média, o plantio de 92 exemplares a cada quilômetro de calçada, podendo assim, 


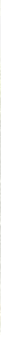

também aumentar a variabilidade de espécies utilizadas, que além de estar muito concentrada em uma única espécie, esta é considerada inadequada para o plantio em passeios públicos, devido ao seu sistema radicular. Em relação ao porte das árvores encontrou-se um equilíbrio entre as três categorias consideradas, o que pode representar um plantio homogêneo no decorrer do tempo, embora muito insipiente. Deve-se considerar que o desenho urbano e o dimensionamento dos espaços urbanos e sua infraestrutura, ainda que não tenha sido escopo deste estudo (limitação de sua abordagem), são de fundamental importância para o planejamento de uma arborização de qualidade. Os dados de compatibilidade sugerem essa deficiência, uma vez que grande parte das árvores foram consideradas grandes para o espaço existente, revelando a necessidade de legislação que garanta dimensões físicas mais apropriadas dos espaços públicos urbanos. É relevante considerar que o mercado imobiliário busca tirar o maior aproveitamento possível das áreas loteáveis como espaço privado, vendável, garantindo, muitas vezes, apenas as medidas mínimas dos espaços públicos e infraestruturas, especialmente das calçadas e passeios públicos. A garantia em lei de medidas mínimas mais generosas desses espaços, poderia contribuir para uma cidade mais qualificada, acessível e humana.

A elaboração de um Plano Diretor de Arborização (PDAU) é essencial para organizar esta infraestrutura. Embora o município não disponha deste plano, existe uma iniciativa recente de padronização e a elaboração de um guia de arborização, numa parceria entre a Prefeitura Municipal e a Universidade Estadual Paulista (Unesp) campus Registro (REGISTRO, 2017). A percepção negativa da arborização encontrada junto aos moradores entrevistados é condizente com os dados objetivos da arborização, especialmente a variável abundância de árvores.

O presente artigo alcançou os objetivos propostos, e apesar das limitações inerentes ao desenho metodológico apresenta um indicativo da qualidade da arborização urbana de Registro/SP, indicando a necessidade de um maior planejamento e engajamento político para garantir uma cidade mais verde. Aponta-se para novos estudos que consideram a relação da arborização com a saúde urbana, especialmente a percepção da qualidade de vida urbana.

\section{REFERÊNCIAS BIBLIOGRÁFICAS}

BACKERS, Fernanda Alice Antonello Londero; GIRARDI, Leonita Beatriz; NEUHAUS, Mauricio. BELLÉ, Rogério Antonio; SCHWAB, Natalia Teixeira; PEITER, Marcia Xavier. Caracterização das espécies utilizada na arborização urbana em Silveira Martins, RS. Revista Brasileira de Horticultura Ornamental, 17(2): 167-174, 2011.

CAMPO GRANDE. Secretaria Municipal de Meio Ambiente e Desenvolvimento Urbana. Plano Diretor de Arborização Urbana - PDAU. Campo Grande, 2010.

CARASEK, Mirin; MELO, Evanisa Fátima Reginato Quevedo; MELO, Ricardo Henryque Reginato Quevedo. Parques Urbanos na promoção da qualidade de vida: estudo de caso em Passo Fundo, RS. Rev. Nac. Gerenc. Cidades, 5(35): 55-67, 2017.

CASTRO, Hugo Santos de; DIAS, Teresa Cristina Albuquerque de Castro. Percepção ambiental e arborização urbana em Macapá, Amapá. Biota Amazônia, 3(3): 34-44, 2013.

COSTA, Renata Geniany da Silva; FERREIRA, Cássia de Castro Martins. Análise do índice de áreas verdes (IAV) na área central da cidade de Juiz de Fora, MG. REVSBAU, 4(1): 39-57, 2009. 


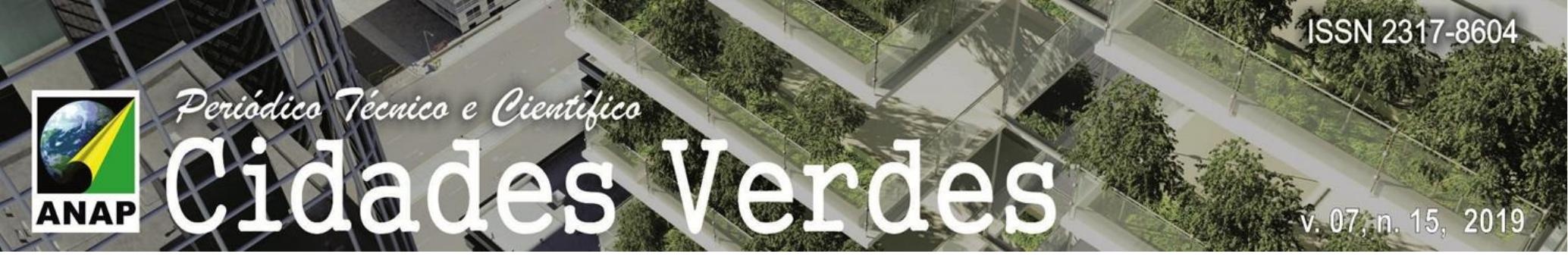

CRISPIM, Diêgo Lima; MENESES, José Alison Dias de; VIEIRA, Artur Sales de Abreu; ARAÚJO, Lucas Martins de; CRUZ, Josias da Silva; SILVA, José Israel Sousa. Levantamento quali-quantitativa da arborização urbana da cidade de Baixio-CE. Divulgação Científica e Tecnológica do IFPB, 23:99-106, 2017.

FRANÇA, Tainã Potiguara Pereira de; SANTOS, Carla Zoaid Alves dos; GOMES, Laura Jane. Arborização de Aracaju: uma percepção dos seus moradores. Geografia, 21(2): 05-22, 2012.

GALLO, Douglas. Desenvolvimento sustentável e qualidade de vida: reflexões sobre vulnerabilidade e resiliência urbana. Fórum Ambiental Alta Paulista, 13(2)): 44-56, 2017.

GALLO, Douglas Luciano Lopes; GUARALDO, Eliane. Análise da arborização de acompanhamento viário de Campo Grande-MS: distribuído pelas microbacias. In: XIV CONGRESSO BRASILEIRO DE ARBORIZAÇÃO URBANA, 2010, Bento Gonçalves-RS. Anais... Sociedade Brasileira de Arborização Urbana, Bento Gonçalves, 2010.

GALLO, Douglas Luciano Lopes; GUARALDO, Eliane. A arborização de acompanhamento viário no estado de Mato Grosso do Sul: os espaços livres como palco da vida. In: SILVA, Isabel Corrêa da; PIGNATELLI, Marina; VIEGAS, Susana de Matos. Livro de Atas do 10 Congresso da Associação Internacional de Ciências Sociais e Humanas em Língua Portuguesa. 1. ed., Lisboa: Leading Congressos, 2015.

GALLO, Douglas; GUARALDO, Eliane. Arborização urbana como infraestrutura na constituição de uma cidade com qualidade de vida: potencialidades em Campo Grande/MS. Rev. Nac. Gerenc. Cidades, 5(31): 78-89, 2017.

GALLO, Douglas Luciano Lopes; LOGSDON, Louise. Diagnóstico da arborização de acompanhamento viário em conjuntos habitacionais. E\&S, 7(1):2-14, 2018.

HUNTHER, Márcia Cristina; MASCARÓ, Juan José. Análise qualitative da arborização urbana em bairros de diferentes classes sociais. Malha Urbana - Revista Lusófona de Urbanismo, 4(6), 2008.

IBGE, Instituto Brasileiro de Geografia Estatística. Cidades: Registro/SP. Censo, 2010. Disponível em: < https://cidades.ibge.gov.br/brasil/sp/registro/panorama>, Acesso em 02 jul. 2018.

LONDE, Patrícia Ribeiro; MENDES, Paulo Cezar. A influência das áreas verdes na qualidade de vida urbana. Hygea, 10(18): 264-272, 2014.

MASCARÓ; Lucia; MASCARÓ, Juan. Vegetação Urbana. Porto Alegre: Mais Quatro Editora, 2. ed., 2005.

MELO, Rafael Rodolfo de; LIRA FILHO, José Augusto de; RODOLFO JÚNIOR, Francisco. Diagnóstico qualitativo e quantitativo da arborização urbana no bairro Bivar Olinto, Patos, Paraíba. REVSBAU, 2(1): 64-80, 2007.

MENEGUETTI, Gabriela Ignarra Pedreira. Estudo de dois métodos de amostragem para inventário de arborização de ruas dos bairros da orla marítima do município de Santos/SP. Dissertação (Mestrado), Piracicaba, 2003.

MILANO, Miguel Serediuk. Métodos de amostragem para avaliação da arborização de ruas. In: II CONGRESSO BRASILEIRO DE ARBORIZAÇÃO URBANA, 1994, São Luis. Anais... Sociedade Brasileira de Arborização Urabana, São Luis, v. 1, p. 163-168, 1994.

OLIVEIRA, Flávio Augusto Cella de; SILVA, Lenir Maristela; HASSE, Ionete; CADORIN, Daniele Acco; OLIVEIRA, Kleber Andolfato de. Inventário da arborização do campus Pato Branco da Universidade Tecnológica Federal do Parana - UTFPR. REVSBAU, 4(1): 93-106, 2009.

PAIVA, Ary Vieira de. Aspectos da arborização urbana do centro de Cosmópolis-SP. REVSBAU, 4(4): 17-31, 2009. 


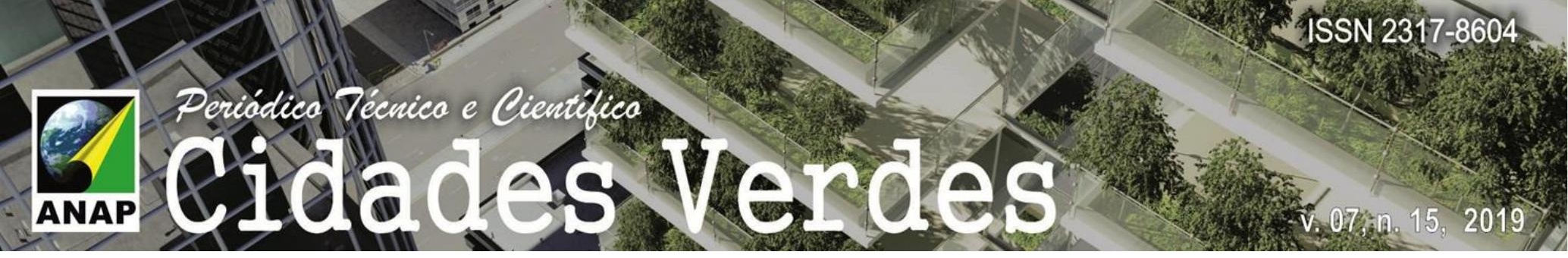

PAULA,Luana de; DUARTE, Matheus Sebastião Silva; TOSTES, Renata Barreto; OLIVEIRA JUNIOR, Paulo Roberto de; RUBACK, Samuel de Souza. Arborização urbana do bairro Centro do município de Cataguases, MG. Revista Agrogeoambiental, 7(2):101-112, 2015.

PINA, José Hermano Almeida. A influência das áreas verdes urbanas na qualidade de vida: o caso dos Parques do Sabiá e Victório Siquierolli em Uberlândia-MG. Dissertação (Mestrado), Uberlândia, 2011.

PINHEIRO, Clebio Rodrigues; SOUZA, Danilo Diego de. A importância da arborização nas cidades e sua influência no microclima. Rev. Gest. Sust. Ambient., 6(1): 67-82, 2017.

PIZZIOLO, Bruna Vieria; TOSTES, Renata; SILVA, Kelly; ARRUDA, Viviane Modesto. Arborização urbana: percepção ambiental dos moradores dos bairros Bom Pastor e Centro da cidade de Ubá/MG. REGET, 18(3): 1162-1169, 2014.

REGISTRO. Prefeitura Municipal de Registro-SP. Guia de arborização urbana do município de Registro. Registro, 2017.

RIO DE JANEIRO. Secretaria Municipal de Meio Ambiente. Plano Diretor de Arborização da cidade do Rio de Janeiro. Rio de Janeiro, 2015.

RODOLFO JÚNIOR, Francisco; MELO, Rafael Rodolfo de; CUNHA, Thiago Augusto da; STANGERLIN, Diego Martins. Análise da Arborização Urbana em bairros da cidade de Pombal no Estado da Paraíba. REVSBAU, 3(4): 3-19, 2008.

ROMERO, Marta Adriana Bustos. A arquitetura bioclimática do espaço público. Brasília: Editora UnB, 2001.

ROPPA, Cristiane. FALKENBERG, Jaiane Rodrigues; STANGERLIN, Diego Martins. BRUN, Flávia Gizele König; BRUN, Eleandro José; LONGHI, Solon Jonas. Diagnóstico da percepção dos moradores sobre a arborização urbana na Vila Estação Colônia - Bairro Camobi, Santa Maria - RS, REVSBAU, 2(2): 11-30, 2007.

SANTANA, Paula. A cidade e a saúde. Coimbra: Gráfica de Coimbra, 2007.

SANTOS, Carla Zoaid Alves dos; FERREIRA, Robério Anastácio; SANTOS, Leila Rafaela; SANTOS, Lívia Isabela; GOMES, Silvio Henrique; GRAÇA, Dalva Angélica. Análise qualitativa da arborização urbana de 25 vias públicas da cidade de Aracaju-SE. Ciência Florestal, 25(3): 751-763, 2015.

SANTOS, Miely Oliveira dos; MAIA, Lizane Paula Santos de Souza; OLIVEIRA, Eudivane Dutra de; SILVA NETO, Cândido André da; CELLA, Wilsandrei. Percepção ambiental sobre a arborização urbana no bairro Santa Tereza, Tefé, Amazonas, Brasil. R. Ra'eGa, 44: 231-241, 2018.

SCHEUER, Junior Miranda. Planejamento urbano, áreas verdes e qualidade de vida. Rev. Meio Amb. e Sustent., 11(5): 59-73, 2016.

SEMA, Secretaria do Meio Ambiente de Aracaju. Plano Municipal de Arborização Urbana de Aracaju-SE. 2. ed., Aracaju, 2014.

TUAN, Yi-Fu. Topofilia: um estudo da percepção, atitudes e valores do meio ambiente. Londrina: Eduel, 2012. 